\title{
Impression and Information Management: On the Strategic Self- Regulation of Innocent and Guilty Suspects
}

\author{
Maria Hartwig ${ }^{*}, 1$, Pär Anders Granhag ${ }^{2}$, Leif A. Strömwall ${ }^{2}$ and N. Doering ${ }^{1}$ \\ ${ }^{I}$ Department of Psychology, John Jay College, City University of New York, USA \\ ${ }^{2}$ Department of Psychology, University of Gothenburg, Sweden
}

\begin{abstract}
The aim of this study was to increase understanding of the psychology of deception by mapping the reasoning of guilty and innocent mock suspects who deny a transgression. Based on previous research, we proposed that suspects will engage in two major forms of regulation: impression management, which requires the purposeful control of nonverbal and demeanor cues; and information management which involves the regulation and manipulation of speech content to provide a statement of denial. We predicted that truth tellers and liars would both be engaged in impression management, but that that they would differ in the extent to which they will engage in information management. The results supported this prediction: liars and truth tellers reported planning demeanor to the same extent, but differed in the extent to which they reported planning the content of their statement. Self-reported strategies regarding nonverbal behavior were similar for liars and truth tellers, while strategies regarding information differed markedly.
\end{abstract}

Keywords: Suspects' strategies, impression management, information management.

The literature on deception shows that lie-catching is an enterprise fraught with error (Vrij, 2000). Lay people achieve hit rates around or slightly above chance level when facing the task of distinguishing between truthful and deceptive statements (Bond \& DePaulo, 2006), including deceptive and truthful denials of crime (Vrij, 2003). Contrary to common sense notions and self-reported accuracy (Kassin et al., 2007) presumed lie experts such as police officers do not fare much better (e.g., Meissner \& Kassin, 2002).

How can this be explained? One reason is that truthful and deceptive behavior in laboratory research differs only minutely, if at all. That deceptive statements are produced with little difficulty suggests that people in general are skilled at lying, which is plausible given the frequency of lying in social life (DePaulo \& Kashy, 1998; Vrij, 2008). Practice makes perfect, as suggested by two bodies of research: one being developmental social cognition research, which suggests that deceptive skills improve as a function of deeper understanding of other minds (Granhag \& Strömwall, 2004); and the other being research on criminals (who arguably practice high-stake deception more frequently than most others, see Vrij \& Semin, 1996; Granhag et al., 2004) who have been found to provide highly believable deceptive statements with little or no preparation (Kassin, Meissner, \& Norwick, 2005).

A second reason that lie-catching is flawed is that people hold incorrect beliefs about the cognitive, emotional and behavioral patterns of liars and truth tellers. For example, people expect liars to experience nervousness, anxiety and arousal and that such experiences will leave visible traces in demeanor (Strömwall, Hartwig \& Granhag, 2004). As noted

*Address correspondence to this author at the John Jay College, City University of New York, USA; Tel: + 1917868 9210; Fax: + 1212237 8930; E-mail: hartwigmaria@gmail.com by Bond and DePaulo (2006), people seem to hold a morally colored prescriptive stereotype of the liar: 'stricken with shame, wracked by the threat of exposure, liars leak signs of their inner torment. They fidget, avoid eye contact, and can scarcely bring themselves to speak' (p. 216; Bond \& DePaulo, 2006). These misconceptions about the deceptive mindset and behavior are widespread (Strömwall, Granhag, \& Hartwig, 2004) and have even been found to be pancultural (Global Deception Research Team, 2006). Additionally, it is a fundamental tendency in human judgment and decision-making to rely on a person's superficial similarity to a stereotype when judging the likelihood of group membership (the representativeness heuristic, Tversky \& Kahneman, 1974).

If common sense notions about the psychological processes of liars and truth tellers are incorrect, how can these processes be captured more correctly? The aim of this study is to increase understanding of the psychology of deception by mapping the strategies and reasoning of guilty and innocent mock suspects who deny a transgression. Expressed differently, we are interested in similarities and differences in self-regulation, processes which pertain to the efforts people employ to reach desired goals and outcomes (Fiske \& Taylor, 2008, Granhag \& Hartwig, 2008). Such knowledge is important for several reasons. First, by approaching the topic from the perspective of self-regulation, we might contribute to the theoretical understanding of lying and truth telling. Second, given that a large proportion of the experimental research on deception focuses on overt behavior (Vrij, 2008), providing some empirical information about the characteristics of deceptive reasoning, planning and strategizing might be warranted for the purpose of understanding the underlying psychological processes at play. Third, it is possible that cues to deception can emerge from liars' strategies to appear honest (DePaulo \& Morris, 2004). Therefore, studying deceptive strategies and attempts 
at self-regulation is a way to possibly improve deception detection (Granhag \& Hartwig, 2008).

In order to provide a theoretical and empirical background and to generate hypotheses about similarities and differences in deceivers' and truth tellers' strategies to be believed, a brief review of the literature is needed. First, we will turn to some theoretical frameworks on the psychology of deception, after which we will review the empirical findings on deceivers' and truth tellers' strategies to be believed.

\section{THEORETICAL BACKGROUND}

\section{The Self-Presentational Perspective}

The self-presentational perspective on deception, outlined and discussed by DePaulo (1992; DePaulo et al., 2003) starts with the assumption that much of social behavior is regulated for the purpose of interpersonal presentation. That is, people aim at coming across as favorable in the eyes of others, and therefore edit and 'groom' their self- presentation to come across the desired way. According to the self-presentational perspective, communicators will manipulate and regulate their behavior to achieve the impression they are motivated to create. We suggest that the self-presentational perspective is relevant for both lying and truth telling in legal contexts: when interacting with law enforcement or other legal professionals, people under suspicion will be strongly motivated to display honest and credibleseeming demeanor. In other words, regulated demeanor is not exclusive to a liar whose veracity is questioned. In line with the self-presentational perspective, we expect that innocent people under suspicion will also be concerned with impression management and will deliberately control themselves to achieve credible demeanor.

\section{The Deception Discrepancy}

The self-presentational perspective (DePaulo et al., 2003) suggests that lying and truth telling is similar in the sense that both communicators are motivated to achieve a favorable impression. However, lying and truth telling is obviously not identical: as emphasized by DePaulo and colleagues (2003), truth tellers' claims of honesty and innocence are legitimate, while liars' are not. Translated to the case of criminal suspects, guilty suspects have a transgression to cover up, while innocent suspects do not. DePaulo and colleagues (2003) have elaborated further as to what extent this deception discrepancy (between the claim of innocence and reality) might give rise to demeanor differences. In this paper, we suggest that the deception discrepancy will have one major consequence for the reasoning of liars and truth tellers: truth tellers who claim innocence will not need to fabricate an account to support this claim as they can draw freely from the self-experienced event. In contrast, the guilty person who claims innocence must engage in information management: they must replace the truthful information about the transgression with a specious account claiming innocence. This emphasis on the difference in the cognitive task of liars and truth tellers has been highlighted by previous theoretical (McCornack, 1992) and empirical work on deception (Colwell, HiscockAnisman, Memon, Woods, \& Michlik, 2006). Drawing on such work, we predict that innocent and guilty suspects will differ in their tendency to manipulate and manage information, with guilty suspects reporting planning this aspect of their behavior to a higher extent than innocent suspects.

\section{EMPIRICAL RESEARCH ON SUSPECTS' REASONING AND STRATEGIES}

The available empirical evidence from laboratory research employing mock crime paradigms shows marked differences in innocent and guilty mock suspects' approach to and perceptions of the situation. In a study where mock suspects were interviewed by experienced detectives, innocent and guilty participants were indistinguishable in terms of overt demeanor, but displayed large differences in their self-reported strategies to accomplish the goal of convincing the interrogator of their innocence (Strömwall, Hartwig \& Granhag, 2006). Guilty suspects reported employing a variety of strategies to be believed. A common strategy involved the distortion of information as a way to conceal the crime without contradicting known facts. Many guilty suspects' intention was to provide a simple and streamlined statement to avoid both within-statement contradictions and contradictions with facts known by the interrogator.

In contrast to guilty suspects, innocent suspects approach the interview less concerned with strategic information management and instead seem to focus on providing a complete and unedited account as a way to prove their innocence. In a series of studies, innocent mock crime suspects have been found to operate on the notion that the truth is good enough, and if they simply provide an account of what happened, they will be exonerated (Hartwig, Granhag \& Strömwall, 2007; Strömwall, Hartwig \& Granhag, 2006). Additionally, such findings on innocent suspects' self-reported strategies of forthcomingness is mirrored and expanded upon by recent research on innocent people's behavioral choice in mock crime investigations. First, innocent ( $v s$ guilty) mock suspects are more likely to waive their rights to silence and participate in interrogations during investigations (Hartwig, 2005; Kassin, 2005). Second, analyses of innocent suspects' beliefs indicate that they feel they are likely to be successful in convincing the interviewer because of a belief that their innocence is somehow visible and that the interviewer will perceive it.

Innocent suspects' belief that their state of mind is selfevident can be connected to the illusion of transparency (Gilovich, Savitsky \& Medvec, 1998), showing that people systematically overestimate the extent to which internally experienced processes leave visible traces for others to see. Similar to the curse of knowledge, which involves a tendency for one to be biased by one's own current expertise on an issue when inferring another's understanding (Birch \& Bloom, 2007), the illusion of transparency suggests that people cannot sufficiently discount the phenomenology of their own experiences when making inferences about the knowledge of others. Further, innocent suspects' attitude towards questioning echoes the fundamental justice motive: people hold a motivated belief that the world is fair and that bad things do not happen to undeserving people (Hafer \& Bègue, 2005). The belief in the justness of the world is echoed and possibly amplified in the mind of the innocent: one does not expect that unfair things could happen to others who do not deserve it, and one might be even more resistant 
to believe that unfair things could happen to oneself. Much social cognitive research shows that the self-concept is enhanced by a number of self-serving biases (Tesser, 2001; von Hippel, Lakin, \& Shakarchi, 2005), further supporting the notion that beliefs about the fairness of the world might be particularly pronounced for assessments pertaining to oneself. In line with these predictions on distorted expectations of success, experimental research has shown that innocent ( $v s$ guilty) mock suspects are more likely to waive their rights to a line-up in favor for a one-person show-up, referring explicitly to their innocence as the reason for having little to no fear of misidentification (Holland, Kassin, \& Wells, 2005).

In summary, based on previous theoretical and empirical research, we propose that people who attempt to escape punishment for a transgression will engage in two major forms of regulation: impression management, which requires the purposeful control of nonverbal and demeanor cues and information management which involves the regulation and manipulation of speech content to provide a statement of denial. We predict that truth tellers and liars will both be engaged in impression management (entailing the suppression of undesirable negative emotions and nervousness in favor of stereotypically honest, calm and collected behavior), but that that they will differ in the extent to which they will engage in information management (Hypothesis 1). In line with previous research on mock suspects' reasoning, we predict that guilty suspects will be more likely than innocent suspects to approach questioning armed with an explicit strategy (Hypothesis 2; Strömwall et al., 2006). In line with theory on the belief in a just world, we predict that innocent suspects will have a more positive outcome expectation, the manifestation of which will be seen in more pronounced beliefs that their statement will be perceived to be credible (Hypothesis 3 ). We also predict that the principal strategies of guilty suspects will concern the management of information. In contrast, innocent suspects' strategies will to simply provide an account of what happened, indicating a belief that their truthful statement is good enough (Hypothesis 4; see also Hines, Colwell, Hiscock-Anisman, Ansarra, Memon, \& Garrett, 2010).

\section{METHOD}

\section{Overview}

The experiment consisted of two phases. In the first phase, participants (hereafter referred as the suspects) were randomly assigned to either commit a mock crime in the form of a theft of a wallet or engage in a non-criminal act. During the second phase, the suspects were told that they were suspected of stealing a wallet and that they would be interviewed about their whereabouts and actions. In relation to the second phase, we measured the strategies and reasoning of the mock suspects as a function of guilt/innocence to test the proposed hypotheses.

Participants. The group of participants acting as suspects consisted of 96 undergraduate students (66 women, 30 men; mean age 24.38 years, SD = 4.12). All participants were recruited on a voluntary basis and received a movie ticket as compensation for their participation.

Procedure. Participants were randomly allocated to the guilty $(n=48)$ and innocent $(n=48)$ condition and received written instructions informing them that they had the right to leave the experiment at any time. The innocent participants were instructed to go to the department library and look for a book that was located in a box filled with books adjacent to a window. On top of this box lay a briefcase that was slightly opened. In order to look for the book in the box they had to remove the briefcase. If they did not find the book within one minute time they were instructed to leave the library. The book was not in the box, and all innocent subjects subsequently left the library empty-handed.

The subjects in the guilty condition were also instructed to go to the library, but to commit a mock crime. They were instructed to enter the library and to look for a briefcase containing a wallet. This briefcase was located on the box filled with books. Their task was to steal the wallet with money when they thought nobody was watching. After taking the wallet, they were to hide it from view (e.g., put it in their pocket or hide it under their clothes) and immediately exit the library. They were instructed not to talk to anyone during the entire procedure. It was made explicit that they did not commit a real transgression as the wallet belonged to the experiment.

Both guilty and innocent suspects were watched by an experimenter who was in the library. This experimenter made sure that the participants complied with the instructions and that anyone else entering the library was informed that an experiment involving a staged theft was taking place.

After having committed the criminal or non-criminal act, the participants went to a second room in which they had to perform a filler task for 10 minutes. After this, they were informed that a theft had taken place, that they were a suspect in the case and that they soon would be interviewed about the matter. They were told that their main task during this interview was to convince the interviewer that they were innocent of the crime and they were instructed to take the precautions esteemed necessary to accomplish this task.

\section{Dependent Variables}

After the interrogations, the suspects were given a questionnaire containing questions about their age and sex, and as a part of a manipulation check were asked to rate the truthfulness in their story on a 10-point scale, where 1 indicated totally deceptive and 10 totally truthful. On scales ranging from 1 (no, not at all) to 10 (yes, very much) they rated how nervous they had been during the interview, how cognitively demanding they had found the interview, and to what extent they were motivated to fulfill the task. The participants further rated the degree to which they had planned the verbal content of their statement as well as the degree to which they had planned their nonverbal behavior on rating scales ranging from 1 (very low degree) to 10 (very high degree). In the questionnaire, they were asked whether they had a strategy before the interview. If they had a strategy, they were asked to write down this strategy; if not, they were asked to provide the reasons for the absence of a strategy. The suspects then rated how satisfied they were with the strategy they had used, 1 (very dissatisfied) to 10 (very satisfied). They answered what veracity judgment they thought the interviewer would make (i.e., truth or lie), after which they were asked to write down why they thought the 
Table 1. Suspects' Strategies before the Interview and Motivations for Not having a Strategy

\begin{tabular}{|c|c|c|c|}
\hline Category & Guilty & Innocent & $t$-Value \\
\hline \multicolumn{4}{|l|}{ Strategy } \\
\hline Tell the whole truth & - & $18(37.5 \%)$ & $5.31 * * *$ \\
\hline Avoid lying & $12(25 \%)$ & $2(4.2 \%)$ & $3.00^{* *}$ \\
\hline Act calm and relaxed & $6(12.5 \%)$ & $5(10.4 \%)$ & $0.32, \mathrm{~ns}$ \\
\hline Provide innocent reason for being at scene & $8(16.7 \%)$ & -- & $3.07 * *$ \\
\hline Deny/avoid incriminating details & $4(8.3 \%)$ & $1(2.1 \%)$ & $1.38, \mathrm{~ns}$ \\
\hline Other & $9(18.8 \%)$ & $8(16.7 \%)$ & $0.27, \mathrm{~ns}$ \\
\hline \multicolumn{4}{|l|}{ No Strategy, Motivation } \\
\hline Innocent, therefore do not need one & -- & $19(39.6 \%)$ & $5.55 * * *$ \\
\hline Did not know what would happen & $5(10.4)$ & $8(16.7 \%)$ & $0.89, \mathrm{~ns}$ \\
\hline Spontaneity/unrehearsed story & $8(16.7 \%)$ & $2(4.2 \%)$ & $2.03^{*}$ \\
\hline
\end{tabular}

Note: Number represents frequency of reporting the strategy, number within parentheses indicate percentage of all guilty or innocent suspects who reported this strategy. The category labeled other represents those strategies that simply referred to acting in a credible fashion without any narrower description and a few strategies that were only mentioned by one suspect and hence could not be argued to form a category of its own (these included being nice/polite, cooperating with interviewer).

$*=\mathrm{p}<.05 ; * *=\mathrm{p}<.01 ; * * *=\mathrm{p}<.001$.

interviewer would make that judgment. They were asked to assess how hard it would be for a person watching the videotaped interview to make a veracity assessment from 1 (very easy) to 10 (very difficult). After finishing the questionnaire, they were thoroughly debriefed, thanked and rewarded for their participation.

\section{Qualitative Analyses of Self-Reported Strategies}

A random $20 \%$ of the responses to the open-ended question regarding strategies (e.g., if they had a strategy, what it was; and if they did not have a strategy, the reason for this) were coded by two female graduate students in psychology who had previous experience coding similar responses. They employed a data-driven coding procedure, meaning that the categories of strategies were derived from the data rather than pre-defined. After inter-rater agreement figures had been calculated, one coder proceeded to code all of the material. The inter-rater agreement was $95 \%$, meaning that $95 \%$ of the responses were coded identically by the two coders. The categories are reported in Table $\mathbf{1}$.

\section{RESULTS}

\section{Manipulation Check and Preliminary Analyses}

Prior to the data analysis, we conducted a preliminary analysis in order to check whether participants complied with the instructions to lie or tell the truth. An independentsamples t-test was conducted to compare the truthfulness scores for liars and truth-tellers. There was a strong significant difference in scores for liars (see Table $\mathbf{2}$ for means, standard deviations and details on the statistical tests), indicating that the manipulation of truthful and deceptive denials was successfully accomplished.

\section{Hypothesis Tests}

\section{Planning, Perception of Interview and Strategies as a Function of Veracity}

We ran independent-sample t-test to establish the effect of guilt and innocence on the preparation for, and experience of, the mock investigation (see Table 2 for means, standard deviations and details on the statistical tests). As can be expected, the mock crime event was rated as eliciting more nervousness and discomfort compared to the non-criminal event experienced by the innocent suspects.

Table 2. Comparisons Between Liars and Truth Tellers, 1-10 Ratings

\begin{tabular}{|c|c|c|c|c|c|}
\hline \multirow{2}{*}{ Variable } & \multicolumn{2}{|c|}{ Liars } & \multicolumn{2}{|c|}{ Truth Tellers } & \multirow{2}{*}{$t$-Value } \\
\hline & $\mathbf{M}$ & SD & $\mathbf{M}$ & SD & \\
\hline Truth degree & 5.51 & 2.46 & 9.92 & 0.28 & $12.22 * * *$ \\
\hline Motivation & 8.25 & 1.63 & 8.69 & 1.50 & $1.37, \mathrm{~ns}$ \\
\hline Nervous, event & 4.19 & 2.88 & 3.13 & 2.25 & $2.02 *$ \\
\hline Unpleasant, event & 3.79 & 3.08 & 2.02 & 1.56 & $3.55 * *$ \\
\hline Nervous, interrogation & 4.92 & 2.36 & 4.48 & 2.54 & $0.87, \mathrm{~ns}$ \\
\hline Cognitively demanding & 4.67 & 2.81 & 3.33 & 2.17 & $2.60 *$ \\
\hline Planning verbal content & 4.67 & 2.44 & 3.33 & 2.23 & $2.79 * *$ \\
\hline Planning nonverb demeanor & 3.04 & 2.53 & 2.25 & 2.22 & $1.63, \mathrm{~ns}$ \\
\hline
\end{tabular}

Note: $*=\mathrm{p}<.05 ; * *=\mathrm{p}<.01 ; * * *=\mathrm{p}<.001$.

It was found that neither nervousness ratings nor motivational differences to accomplish the goal differed by veracity. We found that while guilty and innocent suspects reported having planned nonverbal demeanor to the same extent, guilty suspects had planned verbal content to a significantly higher extent than innocent suspects. This supports Hypothesis 1 about impression and information management. In support of Hypothesis 2, chi-square analyses of the dichotomous dependent variables revealed that guilty suspects were significantly more likely to report having devised a strategy for the questioning than innocent suspects (see Table 3). In support of Hypotheses 3, results showed that innocent suspects were significantly more satisfied with their interview performance and estimated the likelihood of success as significantly higher. 
Table 3. Comparisons Between Liars and Truth Tellers, Dichotomous Measures

\begin{tabular}{|c|c|c|c|c|c|}
\hline \multirow{2}{*}{ Variable } & \multicolumn{2}{|c|}{ Liars } & \multicolumn{2}{|c|}{ Truth Tellers } & \multirow{2}{*}{$\chi^{2}$-Value } \\
\hline & Yes \% & No $\%$ & Yes \% & No $\%$ & \\
\hline Did you have a strategy before the interrogation? & 75 & 25 & 50 & 50 & $5.38^{*}$ \\
\hline Satisfied with acting during interrogation? & 54 & 46 & 79 & 21 & $5.36^{*}$ \\
\hline Will the interviewer believe you? & 19 & 81 & 87 & 13 & $40.20^{* * *}$ \\
\hline
\end{tabular}

The coding of the open-ended responses (described in the method section and reported in Table 1) broadly supports Hypothesis 4, which postulated that the principal strategies of guilty suspects would concern information management. Exploring further the types of strategies used by guilty suspects, it was found that the two most commonly reported strategies of guilty suspects were to avoid lying and to provide an 'innocent' reason for being at the crime scene. In contrast, by far the most frequently reported strategy by innocent suspects was to tell the whole truth. A large number of innocent suspects also claimed to not need a strategy, and the principal justification for this was precisely their innocence.

\section{DISCUSSION}

In this study, we proposed and tested a number of predictions related to the strategies and behavioral regulation of innocent and guilty mock suspects. We predicted that in a situation of suspicion, both innocent and guilty suspects will engage in impression management to achieve the goal of being judged as credible. However, their reasoning will differ in certain respects. For guilty suspects, we predicted that their primary focus would be on information management, such as avoiding contradictions with known facts and/or keeping the story simple. In contrast, and in line with social psychological research on cognitive biases (Gilovich, Savitsky \& Medvec, 1998) and on the justice motive (Hafer \& Bègue, 2005), we expected that innocent suspects will operate on the notion that the truth is good enough and that they therefore will be less concerned with the verbal characteristics of their denial.

The results show that self-reported levels of motivation to be believed were high across innocent and guilty suspects, which speaks to the external validity of the experiment. Of course, we do not suggest that these motivation levels approximate those experienced by real crime suspects. However, given that the mean ratings were very high (above 8 on a 10 -point scale), we believe it is warranted to say that we managed to create a situation in which participants were concerned about the outcome and employed effort to succeed, which allows for some possibilities to generalize to real-world settings.

\section{Impression and Information Management}

In line with our first hypothesis, innocent and guilty suspects reported having planned nonverbal behavior to the same extent. This finding is in line with the selfpresentational perspective (DePaulo, 1992; Goffman, 1959), which applied to the current setting emphasizes the fact that both truth tellers and liars edit their self-presentation to come across as honest. Research on subjective cues to deception has shown that there is little variation in beliefs about prototypically deceptive behaviour with evidence that such beliefs are even to some extent pancultural (Global Deception Research Team, 2006). Therefore, people who attempt to be believed to be innocent can thus be expected to be aware of such stereotypical cues to deception and deliberately attempt to orchestrate behaviors counter to the stereotype. Our results thus suggest that voluntary and deliberate control of nonverbal behavior is not unique to deceivers and that truth tellers engage in such editing and manipulation of non-verbal behavior for the sake of perceived credibility. The self-reported strategies to be believed (see Table 1) supports this in that deceivers and truth tellers similarly reported the strategy to act calm and relaxed, which again suggests that attempted control is indicative not so much of deception, but of the appraisal of a situation demanding credible demeanor.

While there was no difference between innocent and guilty suspects in the amount of planning of non-verbal behavior, they differed in the amount of preparation of verbal content (further supporting Hypothesis 1). This lends support to our main line of reasoning that guilty and innocent suspects differ in a central respect: that of information management. Innocent suspects do not seem to feel the need to engage in strategic information management by planning or preparing their statement. This is intuitively appealing as innocent suspects do not usually have guilty knowledge (unless they have witnessed the transgression). In contrast to guilty suspects, they simply have nothing to hide or cover up. The results of this study suggest that while truthful and deceptive deniers both deliberately manipulate their demeanor to give a credible impression, they differ in the extent to which they deliberately manipulate and plan the verbal content of their statement. The finding that innocent suspects are less concerned about information management and are less likely to deliberately manipulate this aspect of their presentation compared to guilty suspects is not surprising. What is more surprising is that this fundamental difference in the task of truthful and deceptive deniers has not been emphasized and studied further in research on deception. While impression and demeanor cues to deception rarely warrant optimism (DePaulo et al., 2003; Kassin, 2008), differences in the challenges related to formulating the verbal statement of denial is likely to be a more fruitful avenue (Vrij, 2008; Vrij et al., 2008). In particular we suggest that experimental research ought to exploit the challenges guilty suspects face in terms of information management and to explore ways of making it more difficult for them to produce a credible denial. 


\section{Strategic Self-Regulation of Innocent and Guilty Suspects}

Most scholarly definitions of deception emphasize the deliberate nature of the task, such as that it entails purposefully attempting to create false beliefs in another (DePaulo et al., 2003; Ford, 2006; Langleben, Dattilio, \& Gutheil, 2006; Toma, Hancock, Ellison, 2008). Despite this, interpersonal deception research has largely mapped the overt behavior of liars rather than their deliberate strategies to accomplish their goals. This is unfortunate, as the psychology of lying in our view is not only a social psychological task of self-presentation, but a goaloriented task involving purposeful regulation of both overt behavioral displays and information. This was the basic theoretical premise of our experimental investigation. We examined strategies of such self-regulation, and we are able to draw several conclusions about the reasoning of innocent and guilty suspects.

First, and in line with our predictions, we found that guilty suspects were more likely than innocent suspects to employ a strategy for the interview. Innocent suspects often rationalized a lack of strategy by a self-sufficient reference to innocence itself ("I am innocent, therefore I do not need a strategy"). When innocent suspects did have a strategy, it was straightforward in nature and typically involved a complete provision of episodic information ("If I tell the truth about what happened, the interviewer will believe me").

Second, regarding the particular strategies used by guilty suspects, it was found that they were more likely to purposefully plan and strategize with regards to their behaviour (Hines et al., 2010). Even the most common justification by guilty suspects for having no strategy (referring to the desire to produce spontaneous and unrehearsed behavior) seems conspicuously strategic, as it represents a form of opposite to attempted control and aims at the production of an effortless flow of behavior. This result suggests that at least some guilty suspects are cognizant of the risks that displaying overly controlled demeanor can pose and that they employ purposeful cognitive strategies (avoiding to prepare a plan for behavior) to avoid falling in this trap. The most common strategy offered by guilty suspects pertained to minimizing the amount of lying. This indicates an understanding of the risks that getting tangled up in contradictions and losing credibility by violating facts known by the lie-catchers can foment (which indeed can have a detrimental effect on their perceived credibility, see Hartwig, Granhag, Strömwall, \& Kronkvist, 2006). Further, another common strategy was to prepare a non-criminal justification for being at the crime scene, which suggests that liars are aware that some facts might indicate their guilt and that they need to produce a denial which conforms to such known facts. These two strategies, which were the most frequently reported by guilty suspects, indicate that there is both a concern for information management and that various strategies are employed by guilty suspects to minimize the risks of contradicting known facts.

Lastly, regarding outcome assessments, innocent suspects were largely convinced that they were successful in convincing the interviewer of their innocence. The difference between innocent and guilty suspects in this respect was unambiguous, and the strong expectation of task success for innocent suspects indicates support for what we suggest may be a link between the mindset of innocence and self-efficacy (Bandura, 1991). Why do innocent suspects have such a positive outcome expectation?
The experimenters conducting the interviews were blind to condition, and therefore we find it unlikely that they provided systematically different feedback to innocent and guilty suspects. It is possible that the belief in a just world is responsible for this optimism bias (Hartwig, 2005). However, a complementary explanation invokes the theoretical framework of self-efficacy, a topic explored extensively in social cognition research. Self-efficacy is an internal assessment that measures if one has, or is capable of obtaining, the necessary skills that are essential for the execution and completion of a particular task or goal (Bandura, 1991; Bandura \& Locke, 2003). Individuals who have high levels of efficacy are more likely to accept and strictly adhere to a challenging goal as well as are increasingly likely to persevere in the face of mounting difficulties (Bandura, 1991; Bandura \& Locke, 2003; Bandura, 1998). They are also likely to demonstrate more proactive behavior, engage in active problem-focused strategies and to make optimistic appraisals of success (Karademas, Kafetsios \& Sideridis, 2007; Gleitman, Fridlund \& Reisberg, 2004; Bandura \& Locke, 2003). Furthermore, regarding success appraisals, recent studies have found that high levels of self-efficacy is associated with an optimism bias which has the potential to influence the individual's interpretation of external information (Karademas, Kafetsios \& Sideridis, 2007; Rimal \& Morrison, 2004). It is possible that the self-efficacy beliefs of innocent suspects might have caused them to interpret neutral feedback from the interviewer in a positive light. As other scholars have pointed out, innocence itself seems to put innocent suspects at risk for misclassification as they fearlessly submit themselves to guilt-presumptive and accusational interrogations and refer to innocence itself as protection against incrimination (Kassin, 2005). We thus extend this research by linking the mindset of innocence to the theoretical construct of self-efficacy, showing that innocent suspects believe there is no risk in being questioned not only because they believe in the fairness of the world (Kassin \& Norwick, 2004), but because they put faith in their own capacity to convince the interviewer of their innocence.

\section{LIMITATIONS AND FUTURE DIRECTIONS}

As described above, we hypothesized that innocent suspects would be forthcoming with information and would trust that their truthful statement would afford them ample protection against misjudgment. We suggested that the belief in a just world might drive this forthcomingness as well as the trust they place in their own innocence as a protection, as people in general tend to believe that they receive the outcomes they deserve (Hafer \& Bègue, 2005). However, our ability to conclusively establish a causal link between the belief in a just world and verbal forthcomingness is limited as we did not measure or manipulate just-world beliefs. Future research ought to address this to provide firm evidence regarding what role these beliefs have in the reasoning of innocent suspects.

We found that innocent suspects did not report engaging in information management and that they simply aimed at 'telling the truth like it happened'. However, it is possible that the tendency to engage in information management might be more pronounced if the target event is less salient to an innocent suspect than in the current experimental study. For example, if an innocent suspect is suspected of a crime that happened several months or even years ago, it might be difficult for $\mathrm{him} / \mathrm{her}$ to recall their exact whereabouts and actions at that 
time. In such situations, the conclusions from this research might not apply as the truthful event is not readily retrievable. Such a situation would demand strategies of innocent suspects which we were not able to map in this study. Future research could investigate this by extending the retention interval between the event in question and the interview.

\section{CONCLUSION}

In conclusion, we found that innocent and guilty suspects were similar in terms of level of motivation, nervousness and impression management during an investigative interview. In contrast, there were large differences in planning and strategizing related to verbal content and information management of guilty and innocent suspects. These differences are anchored in the decision-making challenges of guilty suspects who are forced to make choices about what information to provide or deny (Hilgendorf \& Irving, 1980) and the social cognition and phenomenology of innocence (Bandura, 1991; Fiske \& Taylor, 2008; Gilovich, Savitsky, \& Medvec, 1998; Kassin, 2005). We urge future research to explore these differences further, as they might lead to greater understanding of the psychological processes at play during interviews and interrogations with suspects.

\section{REFERENCES}

Bandura, A. (1991). Social cognitive theory of self-regulation. Organizational Behavior and Human Decision Processes, 50, 248-287.

Bandura, A. (1998). Self-efficacy: the exercise of control. New York: Freeman.

Bandura, A., Locke, E. (2003). Negative self-efficacy and goal effects revisited. Journal of Applied Psychology, 88(2), 87-99.

Birch, S., \& Bloom, P. (2007). The curse of knowledge in reasoning about false beliefs. Psychological Science, 18(5), 382-386.

Bond, C.F., Jr., \& DePaulo, B.M. (2006). Accuracy of deception judgments. Personality and Social Psychology Review, 10, 214-234.

Colwell, K., Hiscock-Anisman, C., Memon, A., Woods, D., \& Michlik, P. (2006). Strategies of impression management among deceivers and truth-tellers: How liars attempt to convince. American Journal of Forensic Psychology, 24, 31-38.

DePaulo, B. (1992). Nonverbal behavior and self-presentation. Psychological Bulletin, 111(2), 203-243.

DePaulo, B.M., \& Kashy, D.A. (1998). Everyday lies in close and casual relationships. Journal of Personality and Social Psychology, 74, 63-79.

DePaulo, B.M., Lindsay, J.J., Malone, B.E., Muhlenbruck, L., Charlton, K., \& Cooper, H. (2003). Cues to deception. Psychological Bulletin, 129, 74118.

DePaulo, R.M., \& Morris, W.L. (2004). Discerning lies from truths: Behavioral cues to deception and the indirect pathway of intuition. In Granhag, P.A. \& Strömwall, L.A. (Eds.). The detection of deception in forensic contexts (pp. 15-40). Cambridge: Cambridge University Press.

Fiske, S.T., \& Taylor, S.E. (2008). Social cognition: from brains to culture. Boston: McGraw-Hill.

Gilovich, T., Savitsky, K., \& Medvec, V.H. (1998). The illusion of transparency: Biased assessments of others' ability read one's emotional states. Journal of Personality and Social Psychology, 75, 332-346.

Gleitman, H., Fridlund, A. \& Reisberg (2004). Psychology. New York: Norton \& Company.

The Global Deception Research Team (2006). A world of lies. Journal of CrossCultural Psychology, 37, 60-74.
Goffman, E. (1959). The presentation of self in everyday life. Garden City, NY: Doubleday.

Hafer, C.L., \& Bègue, L. (2005). Experimental research on justworld theory: Problems, developments, and future challenges. Psychological Bulletin, 131, 128-167.

Hartwig, M. (2005). Interrogating to detect deception. Unpublished Ph.D. thesis. Department of Psychology, Göteborg University.

Hartwig, M., Granhag, P.A., \& Strömwall, L.A. (2007). Guilty and innocent suspects' strategies during a police interrogation. Psychology, Crime and Law, 13, 213-227.

Hines, A., Colwell, K., Hiscock-Anisman, C., Ansarra, R., Memon, A., Garrett, E. (Accepted pending revisions). Impression management strategies of deceivers and honest reporters in an investigative interview. European Journal of Psychology Applied to the Legal Context.

Holland, L., Kassin, S. M., \& Wells, G. L. (2005, March). Why suspects waive the right to a lineup: A study in the risk of actual innocence. Poster presented at the meeting of the American Psychology-Law Society, San Diego, CA.

Karademas, E., Kafetsios, K. \& Sideridis, G. (2007). Optimism, self-efficacy and information processing of threat-and well-being-related stimuli. Stress and Health, 23, 285-294.

Kassin, S.M. (2005). On the psychology of confessions: Does innocence put innocent at risk? American Psychologist, 60, 215-228.

Kassin, S. (2008). False confessions: Causes, consequences, and implications for reform. Current Directions in Psychological Science, 17, 249-253.

Kassin, S., Meissner, C., \& Norwick, R. (2005). 'I'd know a false confession if i saw one': a comparative study of college students and police investigators. Law and Human Behavior, 29, 211-227.

Kassin, S.M., \& Norwick, R.J. (2004). Why people waive their Miranda rights: the power of innocence. Law and Human Behavior, 28, 211- 221.

Langleben, D., Dattilio, F., \& Gutheil, T. (2006). True lies: delusions and liedetection technology. Journal of Psychiatry \& Law, 34(3), 351-370.

McCornack, S. (1992). Information manipulation theory. Communication Monographs, 59(1), 1-16.

Meissner, C.A., \& Kassin, S.M. (2002). "He's guilty!": investigator bias in judgments of truth and deception. Law and Human Behavior, 26, 469480.

Rimal, R. \& Morrison, D. (2004). Understanding the "bias" in optimistic bias: How efficacy determines perceptions of personal vulnerability. Paper presented at the meeting of the International Communication Association, New Orleans, LA.

Strömwall, L.A., Granhag, P.A., \& Hartwig, M. (2004). Practitioners' beliefs about deception. In P.A. Granhag \& L.A. Strömwall (Eds.). The detection of deception in forensic contexts (pp. 229-250). Cambridge: Cambridge University Press.

Strömwall, L.A., Hartwig, M., \& Granhag, P.A. (2006). To act truthfully: Nonverbal behaviour and strategies during a police interrogation Psychology, Crime and Law, 12, 207-219.

Tesser, A. (2001). On the plasticity of self-defense. Current Directions in Psychological Science, 10, 66-69.

Toma, C., Hancock, J., \& Ellison, N. (2008). Separating fact from fiction: An examination of deceptive self-presentation in online dating profiles. Personality and Social Psychology Bulletin, 34(8), 1023-1036.

Tversky, A., \& Kahneman, D. (1974). Judgment under uncertainty: Heuristics and biases. Science, 185, 1124-1131.

von Hippel, W., Lakin, J., \& Shakarchi, R. (2005). Individual differences in motivated social cognition: The case of self-serving information processing. Personality and Social Psychology Bulletin, 31, 1347-1357.

Vrij, A. (2000). Detecting lies and deceit: the psychology of lying and its implications for professional practice. Chichester: John Wiley \& Sons.

Vrij, A. (2008). Nonverbal dominance versus verbal accuracy in lie detection: A plea to change police practice. Criminal Justice and Behavior, 35(10), $1323-1336$

This is an open access article licensed under the terms of the Creative Commons Attribution Non-Commercial License (http://creativecommons.org/licenses/by$\mathrm{nc} / 3.0 /$ ) which permits unrestricted, non-commercial use, distribution and reproduction in any medium, provided the work is properly cited. 